\title{
CONSIDERAÇÕES BIOGRÁFICO-INTELECTUAIS SOBRE UM DIÁlogo VIVO: GEORG LUKÁCS E MAX WEBER NA HEIDELBERG DO INÍCIO DO SÉCULO XX
}

\author{
Mariana Oliveira do Nascimento Teixeira ${ }^{1}$
}

Resumo: Apesar de G. Lukács ser conhecido como um dos mais importantes representantes da teoria marxista, sua formação intelectual não se restringiu à obra de Marx, mas abrangeu um amplo leque de correntes teóricas (muitas das quais com sentido diverso das análises marxianas). Um momento decisivo nessa formação foi sua participação no círculo intelectual em torno de M. Weber, na cidade de Heidelberg, na década de 10 do século passado. Por meio da análise de alguns aspectos do debate intelectual entre Lukács e Weber, das aproximações e dos distanciamentos entre eles, buscamos explicitar o fato de que a influência que um pensador exerceu sobre o outro assumiu uma forma viva e dialógica.

Palavras-chave: Weber, Max; Lukács, Georg; Círculo Max Weber de Heidelberg.

Abstract: Although G. Lukacs is known as one of the most important representatives of Marxist theory, his intellectual development was not confined to the work of Marx, but covered a wide range of theoretical perspectives (many of which have a different standpoint from the Marxian analysis). A turning point in this development was his participation in the intellectual circle around M. Weber, in the city of Heidelberg, at the beginning of the last century. Through the analysis of some aspects of the intellectual debate between Lukacs and Weber, of the approaches and distances between them, we intended to draw attention to the fact that the influence that one thinker had on the other took the active character of a vivid dialogue.

Keywords: Weber, Max; Lukács, Georg; Max Weber Circle in Heidelberg.

${ }^{1}$ Doutoranda do Programa de Pós-graduação em Filosofia da UNICAMP mariana.on.teixeira@gmail.com. 
|98|

Considerações biográfico-intelectuais sobre...

Por mais de cinco décadas a partir de sua adesão ao marxismo (no final de 1918), o filósofo húngaro Georg Lukács refletiu e escreveu sobre temas como estética, teoria política e teoria do conhecimento, procurando pautar-se, sempre, nos escritos de Karl Marx. A extensa obra desse pensador o colocou entre os mais importantes filósofos marxistas do século XX e inclui livros como História e Consciência de Classe (considerado o marco fundador do chamado "marxismo ocidental"2 e que teve uma enorme influência em diversos meios intelectuais marxistas) e A ontologia do ser social (obra incompleta, mas que vem ganhando crescente atenção dos estudiosos, inclusive de maneira especial no Brasil), entre muitos outros. ${ }^{3}$

O foco deste artigo, no entanto, não incide sobre nenhum escrito desse período. Apesar de o próprio autor ter renegado suas obras pré-marxistas (e também do seu "período de transição para o marxismo"), todas as leituras, os debates e a intensa produção teórica lukácsianas anteriores à sua adesão ao marxismo e ao Partido Comunista Húngaro em 1918 exerceram uma duradoura influência sobre o seu modo de pensar a sociedade. O período que muitos estudiosos consideram como decisivo para a formação intelectual de Lukács é aquele compreendido entre 1912 e 1917, em que Lukács frequentou e participou ativamente dos encontros semanais de um grupo de intelectuais que se reunia em torno de Max Weber, em Heidelberg.

A importância da obra do sociólogo alemão para os escritos de Lukács já foi ressaltada inúmeras vezes. Muitos comentadores afirmam, por exemplo, que, em História e Consciência de Classe, Lukács realiza uma síntese original de conceitos de Marx e de

\footnotetext{
${ }^{2}$ Há uma extensa literatura em torno dessa polêmica denominação. $\mathrm{Na}$ impossibilidade dar conta aqui dessa discussão, remetemos somente ao livro que primeiramente conferiu notoriedade ao termo, qual seja, o livro As aventuras da dialética, de Maurice Merleau-Ponty.

${ }^{3}$ É claro que a produção intelectual de Lukács nesses cinquenta anos não constitui um conjunto coeso, pelo contrário: o período é recheado de reviravoltas e auto-críticas - tanto que Mészáros (1996: 222) divide o seu período marxista em nada menos que cinco fases distintas.
} 
Weber ${ }^{4}$ - e o próprio autor reconhece essa importância em mais de uma ocasião. ${ }^{5}$

É sobre as implicações teóricas da convivência e do debate entre os dois pensadores que procuramos lançar luz neste trabalho, a partir da bibliografia existente sobre o tema. ${ }^{6}$ Assim, esperamos deixar claro a partir de nossa argumentação que o caráter da influência de Weber sobre Lukács (e vice-versa) é diferente de quando se trata um pensador lendo o que outro escreveu como um trabalho pronto e acabado. No caso que ora analisamos, trata-se antes de um diálogo que interfere na própria dinâmica da formação intelectual de cada um.

\section{Heidelberg no início do século e o círculo em torno de Max Weber}

De acordo com Éva Karádi, a cidade de Heidelberg se constituiu no início do século passado como a capital intelectual não-oficial da Alemanha. A diversidade de tipos de pensamento é ressaltada por diferentes teóricos, como Emil Lask (com quem, aliás, Lukács travou uma estreita amizade) e o jurista Gustav Radbruch, que compara a cidade a uma Arca de Noé, pois se podia encontrar ali um exemplar de cada nova variedade de pensamento (KARÁDI, 1987: 499). Muitos estrangeiros procuravam

\footnotetext{
${ }^{4}$ Ver, por exemplo: ARATO; BReINEs, 1986: 89; 182 ss.; FeENBERG, 1986: 61-63; HABERMAS, 1984; LÖWY, 1990: 70-71, 73, 75-80; LÖWY, s/d; NoBRE, 2001: 51-57, entre muitos outros.

${ }^{5}$ Ver LuKÁCs, 2003: 5; LuKÁcs (entrevista) apud LöwY, 1990: 80, etc.

6 Para uma descrição desse período da vida de Lukács, ver Congdon, 1983; ARATO; Breines, 1986; LöWY, 1976 e 1990. A descrição presente neste artigo é baseada especialmente nesses três livros e nos trabalhos de Éva Karádi (1987) e Paul Honigsheim (1968). Os testemunhos de Honigsheim, aliás, são considerados uma fonte valiosa para uma descrição desse grupo de intelectuais, visto que o sociólogo participou durante muitos anos de seus encontros semanais e nos deixou extensa documentação sobre o período.
} 
| 100 |

Considerações biográfico-intelectuais sobre...

a cidade às margens do rio Neckar, cujas universidades apresentavam regras em geral mais flexíveis que as encontradas no resto da Alemanha para a admissão de estudantes e intelectuais de outros países. Paul Honigsheim, em suas memórias, afirma que:

A sua universidade [de Heidelberg] era então não somente a mais liberal, mas também a mais internacional da Alemanha. Pessoas que teriam sido excluídas em outros lugares por causa da raça, nacionalidade, política ou religião eram aceitáveis na cidade do Neckar. E então eles estavam todos lá, os representantes de minorias nacionais da Áustria, Hungria e dos países balcânicos, e, por fim mas não menos importante, os russos (Honigsheim, 1968: 1). ${ }^{7}$

Uma espécie de microcosmo desse ambiente existente na cidade podia ser encontrado no Círculo Max Weber de Heidelberg, como ficaram conhecidos os encontros semanais na casa do sociólogo alemão - encontros que foram a maneira que Weber encontrou para conseguir atender a uma parte das inúmeras pessoas que o procuravam para discutir ideias, trabalhos etc. Encontravam-se na casa do sociólogo aos domingos as mais diferentes correntes teóricas e ideológicas: referindo-se ao pensamento de Lukács e Bloch, Honigsheim afirma que "Como quase todo movimento daqueles dias, este reverberou na casa da Ziegelhäuser Landstraße [rua em que morava Weber]" (HonigsheIM ["Der Max-Weber-Kreis in Heidelberg"] apud KARÁDI, 1987: 500). Karádi defende que a atitude positiva de Weber frente a essa diversidade de pensamentos reflete o seu interesse por ideias novas e estimulantes - mesmo que bastante diferentes das suas próprias: "Weber estava interessado nos movimentos intelectuais influentes

${ }^{7}$ Sempre que, como nesse caso, um texto estrangeiro língua for citado em português, a tradução é nossa. 
da atualidade, em ideias e seus efeitos, sem se importar se ele se identificava ou não com elas"' (KARÁdI, 1987: 500).

Alguns dos intelectuais que participavam com maior ou menor frequência desses encontros, entre 1906 e 1918, são: Paul Honigsheim, Ernst Troeltsch, Karl Jaspers, Friedrich Gundolf (que também frequentava o círculo em torno do poeta Stefan George), Alfred Weber (sociólogo da cultura e irmão de Max Weber), os políticos Friedrich Naumann e Theodor Heuss (que se tornaria mais tarde o primeiro presidente da República Federal da Alemanha), os teólogos Hans Ehrenberg e Franz Rosenzweig, o jurista George Jellinek, Nikolai von Bubnov (especialista em Dostoievski), o escritor Feodor Stepan e diversos "místicos e niilistas russos" (ARATO; BREINES, 1986: 89), além de profissionais de outras áreas do conhecimento (como botânica, psiquiatria e medicina). Esporadicamente, participaram também os filósofos neokantianos Wilhelm Windelband, Heinrich Rickert e Emil Lask, e os sociólogos Ferdinand Tönnies, Werner Sombart, Georg Simmel e Robert Michels. Entre os pensadores que buscaram em Heidelberg uma atmosfera intelectual estimulante e que se tornaram presenças constantes na casa de Weber nas tardes de domingo estão também, é claro, Lukács e Ernst Bloch, que haviam se conhecido quando foram alunos de Simmel em Berlim e que eram considerados, na época, dois jovens e promissores (porém ainda desconhecidos) filósofos.

É evidente a impossibilidade de reduzir esse conjunto de pensadores a um denominador comum, a uma ideia unificadora. Um aspecto, não obstante, que tinha forte presença nas discussões semanais, era a crítica à sociedade burguesa contemporânea. Diz Honigsheim: "Mesmo antes da guerra, $[\ldots]$ havia uma tendência que rejeitava o modo de vida burguês, a cultura da cidade, a racionalidade instrumental, a quantificação, a especialização científica, e tudo o mais que era considerado então como fenômenos abomináveis" (Honigsheim, 1968: 79). O autor afirma que Lukács e Bloch, além de Ehrenberg e Rosenzweig faziam parte dessa tendência, que ele chama de "neo-romântica". Honigsheim continua: "Como era o caso com todos os outros 
| 102 |

Considerações biográfico-intelectuais sobre...

movimentos alemães acima do nível do puramente ordinário, o neo-romantismo em suas várias formas estava também representado em Heidelberg; e seus adeptos, como aqueles em vários grupos russos, sabiam na porta de quem deviam bater: na porta de Max Weber" (idem, ibidem). Michel Löwy, em diversos de seus escritos, faz questão de ressaltar esse caráter "romântico anticapitalista" do ambiente intelectual de Heidelberg e, mais precisamente, do Círculo Max Weber. ${ }^{8}$ Cabe ressaltar também - e nisso todos os comentadores concordam - que a literatura e a filosofia religiosa ou mística russas (com destaque para Tolstoi e Dostoievski) exerciam um importante papel nos debates dominicais, apresentando-se como uma alternativa ao individualismo, à quantificação e a tudo o mais que era criticado na sociedade burguesa da Europa ocidental.

\section{Lukács e Weber em Heidelberg}

Lukács foi convencido por Bloch a ir para Heidelberg, uma vez que, na Hungria, dificilmente havia espaço para um debate intelectual e filosófico tão fértil quanto o que eles encontrariam na Alemanha, e especialmente em Heidelberg. Ele estabeleceu-se na cidade em 1912 e lá permaneceu até 1917 (com uma pausa entre outubro de 1915 e julho de 1916, quando teve que prestar o serviço militar na Hungria). Lukács tinha a intenção de, em Heidelberg, realizar seu pós-doutorado sob a orientação de Windelband ou Rickert, ${ }^{9}$ mas acabou aproximando-se realmente de Max Weber, que ficou bastante impressionado com o jovem

\footnotetext{
${ }^{8}$ Ver, por exemplo, os ensaios "Romantismo revolucionário e messianismo místico no jovem Lukács (1910-1919)”, p. 55; “A sociedade reificada e a possibilidade do objetiva do seu conhecimento na obra de Lukács", p. 71 (ambos presentes em LöWY, 1990); e LÖWY, 1976: 45.

${ }^{9}$ Éva Karádi (1987: 503-504) afirma que, apesar dos esforços de Weber de Emil Lask, Lukács não conseguiu suscitar suficientemente o interesse desses importantes pensadores. Não se pode esquecer, também, de
} 
filósofo húngaro e o acolheu em seu círculo intelectual e de amizades. ${ }^{10}$ Lukács reconhece a importância do apoio que recebeu de Weber: "Com alguns, eu encontrei mais compreensão do que nunca em minha vida. Naturalmente eu logo percebi que Max Weber e Lask eram fenômenos extraordinários na vida intelectual da Alemanha naquela época" (LuKÁcs [testemunho] apud KARÁDI, 1987: 503). Andrew Arato e Paul Breines reforçam a importância do Círculo Max Weber para a obra de Lukács do período: "Mas a figura dominante era Weber e a obra de Lukács, de 1912 até os primeiros anos da primeira Guerra Mundial, deve ser vista desde a perspectiva de sua relação com este círculo" (ARATO; BREINES, 1986: 90).

Lukács encontrou, assim, um ambiente intelectualmente instigante e propício para debater suas ideias. Löwy também cita o próprio Lukács a esse respeito: “Foi Bloch quem convenceu Lukács a acompanhá-lo a Heidelberg, onde ele encontrará no Círculo Max Weber o que ele chama de "uma compreensão excepcional de minhas ideias singulares'" (LuKÁcs [Magyar Irodalom, Magyar Kultura] apud LöwY, 1976: 111). Ora, quais são essas "ideias singulares" de Lukács? Löwy as caracteriza, apoiando-se nos testemunhos de Honigsheim, como marcadas por um pensamento "[...] totalmente avesso à burguesia, ao liberalismo, o Estado constitucional, o parlamentarismo, o socialismo revisionista, o Esclarecimento/Iluminismo, o relativismo e o individualismo" (Honigsheim [On Max Weber] apud LÖWY, 1976: 112).

Já de início, Lukács causou um grande impacto em Weber, e vice-versa. Em sua biografia do jovem Lukács, Lee Congdon

que o anti-semitismo existente na sociedade e na academia alemãs decerto contribuiu, ao menos em parte, para a dificuldade que intelectuais de origem judia, como Lukács, encontraram para serem aceitos na universidade (sobre a relação entre a rejeição de Lukács na universidade em Budapeste e suas origens judias, ver CONGDON, 1983: 82-84).

${ }^{10}$ Lukács foi ajudado pela recomendação de Simmel, que aliás, tinha a Lukács e Bloch como dois de seus alunos favoritos (KARÁdI, 1987: 500). 
| 104 |

Considerações biográfico-intelectuais sobre...

afirma que "Lukács causou uma enorme primeira impressão em Weber, com quem ele iniciou intensa conversação". ${ }^{11}$ Já Honigsheim, partindo de um comentário elogioso de Lukács com relação a Weber, aponta que:

Esse último comentário de Lukács, mencionado acima, mostra não apenas seus mais internos sentimentos mas também a impressão profunda que Max Weber causou nele. O sentimento era mútuo. Os dois homens discutiam muitas coisas, articularmente problemas estéticos. [...] Além das discussões teóricas sobre arte, Lukács e Weber debatiam questões marxistas e epistemológicas (HoNigSHEIM, 1968: 27).

Isso não significa, é claro, que havia uma identidade de pensamento entre eles, mas, antes, significa que, mesmo com as diferenças, os dois intelectuais encontravam um no outro uma fonte de inspiração. De acordo com Honigsheim, Lukács tinha várias ideias bastante distintas e até antagônicas às de Weber, mas lembra-se de Weber dizer, apesar disso, que: "Sempre que eu falo com Lukács, eu tenho que pensar sobre isso durante dias" (Weber [testemunho] apud Honigsheim, 1968: 28). Apresentamos, a seguir, alguns pontos de aproximação entre o pensamento de Weber e o de Lukács, especialmente a crítica da racionalidade ocidental como pano de fundo para uma crítica da sociedade burguesa e o interesse pela cultura russa como alternativa a essa sociedade. Por fim, teceremos alguns comentários sobre a influência que Lukács parece ter tido sobre o importante sociólogo alemão.

${ }^{11} \mathrm{O}$ mesmo autor afirma que também Marianne Weber apreciava bastante a companhia e as discussões com Lukács, que cativava a atenção da maioria dos alemães, por causa da força da sua personalidade e o alto padrão do seu trabalho (CONGDON, 1983: 85). 


\section{Aproximações}

Michel Löwy, em um artigo presente em Romantismo e Messianismo, enfatiza o caráter "religioso" e místico do jovem Lukács que chega em Heidelberg, ressaltando a sua preocupação com o isolamento entre as pessoas e a decadência cultural causados pela sociedade moderna e pelo capitalismo. O seu interesse pela religiosidade (ou, antes, pelo espírito religioso, e não uma determinada religião), e também pelo socialismo, se dá na medida em que ele os vê como movimentos que procuram resgatar os valores coletivistas (da Gemeinschaft, da Kultur) destruídos pelo individualismo burguês (LöwY, 1990: 57). O que Lukács procura nas diferentes correntes místicas é "[...] sua rejeição radical do mundo e a tentativa de transcendê-lo através de um milagre" (LöWY, 1990: 58). Essa posição difere, é claro, daquela de Max Weber, mas elas convergem no que tange a uma visão negativa (não obstante a defesa weberiana de uma ciência livre de valores) das consequências do processo de racionalização que se passa no Ocidente.

De fato, o potencial crítico da obra de Weber, e especificamente sua crítica sui generis do capitalismo e da sociedade burguesa, diz Löwy em Pour une sociologie des intellectuels révolutionnaires, é o que pode explicar a afirmação esperançosa de Lukács de que "Max Weber é o homem que poderia arrancar o socialismo do relativismo miserável produzido pela ação de Franck [um dirigente social-democrata revisionista e direitista, M. L.] e seus semelhantes" (LöWY, 1976: 50). Apesar do filósofo húngaro estar completamente enganado com relação a esse papel atribuído a Max Weber, a sua afirmação nos mostra o reconhecimento da possibilidade da crítica a partir da teoria weberiana.

Lukács compartilhava a crítica weberiana da sociedade capitalista moderna como uma sociedade dominada pela racionalidade, e a saída que ele encontrou, à época, tinha a ver com o misticismo, especialmente o misticismo russo - seu pensamento formava assim, diz Löwy, uma combinação "sui generis da crítica cultural neo-romântica do capitalismo, de uma espiritualidade semi-religiosa e de uma aspiração revolucionária 
| 106 |

Considerações biográfico-intelectuais sobre...

pela mudança social" (LöWY, 1990: 64). Apesar de não ser um místico, "[...] Weber compartilhava o entusiasmo de Lukács pelo misticismo, e em boa parte pelo mesmo motivo: o misticismo, também, estava além da racionalidade" (CONGDON, 1983: 87). Além de Löwy e Congdon, Honigsheim também aponta o interesse que Weber tinha pelo misticismo, ouvindo com atenção os especialistas no assunto que frequentavam as reuniões semanais na sua casa (HonigSHeIM, 1968: 109).

Isso nos leva a mais um ponto de aproximação entre os pensadores: a atração não só pelo misticismo russo, mas pela cultura, a filosofia e especialmente a literatura russas como algo que poderia apresentar alternativas ao "mundo individualista $\mathrm{e}$ seelenlos [sem alma] da sociedade industrial da Europa ocidental" (LÖWY, 1990: 59). Arato e Breines afirmam que "Lukács, junto a Bloch e alguns russos, defendia a ideia de que a cultura eslava e o pensamento místico eram uma alternativa ao 'ascetismo mundano' e à 'ação interessada em um fim" do Ocidente burguês" (Arato; Breines, 1986: 90). Esse interesse, na verdade, pode ser estendido para o Círculo Max Weber em geral:

\footnotetext{
$\mathrm{Na}$ realidade, a referência decisiva para o pensamento religioso de Lukács não é o misticismo católico, judeu ou hindu, mas muito mais (como para todo o Círculo Max Weber) a espiritualidade russa e, principalmente, Dostoievski (LöWY, 1990: 59).
}

Ao tratar do assunto, muitos dos comentadores fazem referência à afirmação de Paul Honigsheim de que não havia um domingo em que Dostoievski não fosse mencionado ou que não se discutisse sobre Tolstoi (Honigsheim, 1968: 81). Os dois escritores não são nem de longe revolucionários, nas palavras de Löwy, mas se opõem à civilização burguesa e ocidental, servindo assim como inspiração para a crítica dessa civilização (LöwY, 1976: 133-134). Para Lukács, a tentativa de Dostoievski e Tolstoi de superar o individualismo "europeu" e a anarquia, a desesperança e a ausência de Deus que o seguem (LukÁcs 
[Solovieff, Arquiv für Sozialwissenschaft] apud LöwY, 1976: 134) permite vislumbrar a conquista de um homem novo e, assim, de um mundo novo, os quais, por sua vez, não estão desconectados da nostalgia de uma humanidade harmoniosa e autêntica (LöWY, 1976: 137).

A importância de Dostoievski para Lukács pode ser atestada pelo seu projeto de escrever uma grande obra sobre o escritor russo. Esse projeto não foi concluído, mas o início do que seria essa obra foi publicado sob o título de A Teoria do Romance, uma das principais obras de sua fase pré-marxista. Ao final desse livro, Dostoievski aparece como o anunciador de uma nova época da história mundial, revelando mais uma vez a leitura "messiânica" que Lukács fazia dele e da própria Rússia, que é, para o filósofo, a expressão mais coerente da ética coletivista religiosa em oposição ao individualismo moral burguês (LöWY, 1990: 63). ${ }^{12}$

Os interesses que Lukács e Weber tinham pelos temas vindos da Rússia acabaram se reforçando reciprocamente. Se, por um lado, Weber já havia estudado e escrito sobre os problemas políticos russos desde $1905,{ }^{13}$ é possível que tenha sido Lukács quem chamou a sua atenção para o "misticismo russo" como contraponto à cultura ocidental. É isso o que afirmam, por exemplo, Arato e Breines:

[...] sua proposta [de Lukács], como muitos já apontaram, contribuiu para que Weber se interessasse pelo 'espírito russo' como uma forma de rechaço coerente e significativo do 'espírito do capitalismo' ante o qual desde 1910 Weber havia

12 Um outro eixo do interesse de Lukács, Weber e dos demais membros do círculo weberiano de Heidelberg por Dostoievski consiste no problema da ética, especialmente no dilema que envolve a contraposição entre uma ética de responsabilidade e uma ética de fins últimos. Voltaremos à questão do interesse de Lukács por problemas éticos mais adiante.

${ }^{13}$ Agradeço à leitura atenta de um parecerista anônimo por chamar a atenção para esse fato. 
| 108 |

Considerações biográfico-intelectuais sobre...

começado a se sentir cada vez mais incômodo. O ensaio de Weber, 'Rechaços religiosos do mundo e suas direções' (1915), foi claramente inspirado nos comentários de Lukács (ARATO; Breines, 1986: 90).

A importância de Lukács para certos aspectos do pensamento de Weber é, aliás, ressaltada e apresentada por vários comentadores, e pode ser atestada também pelo fato de o próprio Weber fazer referência ao filósofo húngaro. E Weber o fez não somente em cartas ou memórias, mas também em um de seus importantes ensaios, "Ciência como vocação", em que Weber se refere aos escritos de Lukács sobre estética (WEBER, 1970: 49). Lukács "realmente exerceu um papel no pensamento de Weber", diz Honigsheim (1968: 25). Arthur Mitzman, em seu livro sobre Max Weber intitulado The Iron Cage, identifica essa presença lukácsiana nos seguintes aspectos da obra de Weber:

Lukács parece ter influído em três aspectos da evolução tardia de Weber: seu interesse pela estética formal, seu interesse pela cultura eslava como desafio anti-modernista a seus valores anteriores, e sua curiosidade - pessoal e sociológica - pelo fenômeno erótico" (MitzMAN, 1976: 239).

Além da já mencionada importância de Lukács no que tange ao interesse crescente de Weber pela cultura russa, que ele começava a ver como uma alternativa ao ascetismo mundano, e do terceiro aspecto (o "fenômeno erótico"), que não nos interessa aqui, Mitzman chama a atenção para os problemas relacionados à arte e à estética introduzidos por Lukács no campo de temas que eram objetos de reflexão para Weber. Para o sociólogo, a forma como Lukács põe o problema da obra de arte - isto é, não como uma questão sobre o seu autor ou sobre o público que a recebe, mas sobre a obra de arte em si mesma - é digna de elogios, e mais que isso, trata-se de um enfoque negligenciado pelos estudos que Weber lera até então e que consiste, na realidade, na “colocação definitivamente correta do problema" (MrTZMAN, 1976: 239). 
O declínio do interesse de Lukács pela estética formal e sua maior preocupação com a relação entre ética e política, no entanto, foi justamente um dos fatores que propiciou o distanciamento entre os dois pensadores. Apresentamos no próximo item esse e outros pontos de distanciamento, tais como o caráter radical da crítica que Lukács faz ao capitalismo, a tendência ensaística da sua produção intelectual, o seu posicionamento contrário à guerra e a aproximação crescente com relação ao marxismo e ao comunismo, a partir da Revolução Russa de 1917.

\section{Distanciamentos}

Como ponto de distanciamento de Lukács com relação a Weber podemos citar, inicialmente, a radicalidade da crítica que Lukács faz à sociedade capitalista - o que o separa não somente de Weber, mas do próprio círculo de intelectuais de que fazia parte. Nas palavras de Michel Löwy:

\footnotetext{
Lukács encontra então um eco favorável à sua Weltanschauung [visão de mundo] no círculo Max Weber, mas ele permanece, no entanto, pela sua orientação ético-revolucionária, relativamente marginal no grupo (LöWY, 1976: 113).
}

O próprio Lukács afirma se considerar um "outsider" entre seus amigos alemães (LuKÁcs [Magyar Irodalom, Magyar Kultura] apud LöwY, 1976: 113, nota 4), pois sua recusa do capitalismo é bem mais extrema que na maior parte dos intelectuais alemães de Heidelberg; ele compartilha com esses intelectuais uma visão de mundo trágica, mas recusa a reconciliação com a sociedade ou a resignação que caracteriza alguns desses intelectuais (LöWY, 1976: 113-114). Isso significa que, se por um lado o componente trágico de seu modo de ver é mais profundo do que o presente em teorias que aceitam uma reconciliação com a sociedade, por outro lado, sua visão é também marcada por uma orientação à superação 
| 110 |

Considerações biográfico-intelectuais sobre...

dessa situação trágica, não aceitando nenhum tipo de resignação. Lee Congdon ressalta esse como um ponto que difere Weber de Lukács. Após apresentar resumidamente os principais aspectos da teoria weberiana sobre o processo de racionalização, o autor afirma que:

\begin{abstract}
Uma tal análise dos tempos não podia senão impressionar Lukács, mas o que ele não podia aceitar era a resignação de Weber. Para o alemão, a racionalização era inescapável, o destino do homem ocidental (CoNGDON, 1983: 86).
\end{abstract}

A recusa de Lukács em se resignar perante a decadência da cultura e dos valores, perante o que ele chamou, citando Fichte, de a "época do pecado total" ou "da perfeita culpabilidade" (das Zeitalter der vollendeten Sündhafigkeit), levou o filósofo a procurar obstinadamente pelas condições e pelo sujeito que seriam capazes de implementar uma transformação radical do existente. Como se sabe, Lukács defende em História e Consciência de Classe e em suas obras daí em diante que somente a classe proletária tem tal capacidade. O caminho que leva do jovem esteta que chega em Heidelberg em 1912 até o líder revolucionário da República Soviética Húngara de 1919 e até o intelectual comunista que publica em 1923 um dos livros de filosofia mais importantes para o marxismo, é um caminho que afasta-se cada vez mais, em diversos aspectos, do ponto de vista de Max Weber.

Antes de passar esses acontecimentos, cabe ressaltar um outro motivo de tensão entre os dois pensadores e amigos. Weber insistia para que Lukács completasse seu trabalho sobre estética, uma obra sistemática que poderia servir para tentar conseguir um posto na universidade. ${ }^{14}$ É verdade que Lukács tinha a

\footnotetext{
${ }^{14}$ Mas esse não era o único motivo: Weber se interessava realmente pelos resultados apresentados por Lukács até então sobre o tema. De acordo com Congdon, "Como Lukács, ele [Weber] acreditava que, sobas condições impostas pela racionalização da vida, a arte possuía um caráter redentor" (CoNGDON, 1983: 87).
} 
intenção de superar o "impressionismo filosófico" que caracterizava a obra de Simmel e construir um sistema filosófico completo e coerente; são muito fortes, contudo, as suas tendências ensaísticas e ele tentou por duas vezes, ambas sem sucesso, completar o seu sistema - tentativas que deram origem, respectivamente, à Filosofia da Arte e à Estética de Heidelberg. Nesses trabalhos, Lukács tenta dar expressão sistemática às suas ideias sobre a arte como criadora de um mundo utópico. Em ambos, apesar das diferenças, ele se apoia na distinção kantiana entre fato e valor para fundamentar a distinção radical entre o mundo alienado - o mundo existente, criado por Deus -, e o mundo utópico - o mundo "luciferiano", expresso na arte (CONGDON, 1983: 94;114).

Enquanto trabalhava na Filosofia da Arte - obra tida em muita consideração por Weber (MARIANNE WeBER [Max Weber] apud Congdon, 1983: 92) -, entretanto, Lukács já pensava em abandonar esse projeto, uma vez que estava mais interessado em escrever um livro sobre Dostoievski. Além disso, com o início da guerra em 1914, suas preocupações teóricas começam a sofrer uma gradativa transformação (voltaremos a esse tema adiante). Ele abandona o trabalho sobre a filosofia da arte e escreve $A$ Teoria do Romance, que é a parte que Lukács conseguiu terminar do livro sobre Dostoievski. Essa obra agradou a vários intelectuais (como Alfred Weber, Ernst Troeltsch, Béla Balázs e especialmente Bloch), mas não a Weber, que achava que o trabalho divergia muito da sua obra sobre estética (CONGDON, 1983: 112).

Para Emil Lask, importante pensador (hoje quase desconhecido) e amigo de Lukács, ele é essencialmente um ensaísta que nunca se manteria num trabalho profissional sistemático, opinião à qual Weber se opunha diametralmente (CONGDON, 1983: 112). Lukács decide, porém, como desejava o sociólogo alemão, retomar os trabalhos sobre filosofia da arte, mas começando praticamente do início e escrevendo uma outra obra (conhecida como Estética de Heidelberg) que, tendo em vista os acontecimentos de 1917, ficou também incompleta. 
| 112 |

Considerações biográfico-intelectuais sobre...

Éva Karádi chega a caracterizar essa fase da produção intelectual de Lukács como uma oscilação entre tendências sistemáticas e tendências ensaísticas, polarizadas nas figuras de Weber e Bloch, e nas obras sobre estética e $A$ teoria do romance, respectivamente. Congdon também aponta essa tensão:

Lukács não completou a Filosofia da Arte, e é de se imaginar se ele poderia tê-lo feito, porque a contradição entre a prosa formal e acadêmica e o espírito utópico que a informava não podiam ser facilmente reconciliados (CONGDON, 1983: 95).

Para este autor, mesmo as obras de Lukács sobre estética formal consistem num "romantismo utópico com uma roupagem acadêmica" (CONGDON, 1983: 93).

Como mencionamos anteriormente, um fator que contribuiu para a mudança de interesses de Lukács e seu gradativo afastamento com relação a Weber e os intelectuais do círculo de Heidelberg foi a guerra: "É sem dúvida a grande crise de 1914, a guerra com seu cortejo de misérias que provocaram essa 'politização' em Lukács" (LöWy, 1976: 131). Essa politização de Lukács implica, entre outras coisas, no recrudescimento de sua posição antimilitarista, totalmente oposta à maioria dos seus colegas alemães. Diversos membros do Círculo Max Weber ficaram entusiasmados com o início da guerra, ${ }^{15}$ que parecia para eles como a abertura de uma possibilidade de ou um catalisador para se recriar uma nova comunidade entre os homens, que são obrigados a se tornarem camaradas face ao perigo (ConGDON, 1983: 96). Diz Löwy: "Por outro lado, por causa da guerra ele [Lukács] começa a se afastar politicamente do círculo de

\footnotetext{
${ }^{15}$ Por exemplo o próprio Weber e sua mulher, Marianne, bem como Lask - que se alistou, foi mandado para o front e morreu em batalha, abalando profundamente Lukács (que já tinha perdido, também na guerra, o amigo Béla Zalai).
} 
Heidelberg, cujas principais cabeças (Max Weber etc.) apoiam o imperialismo alemão" (LöWY, 1976: 131).

O mesmo autor defende que o antimilitarismo de Lukács é a consequência lógica do seu anticapitalismo, pois para o filósofo "[...] a Grande Guerra era uma manifestação típica da reificação e mecanizações capitalistas da vida social" (LöWY, 1976: 131). É certo que Lukács achava que, como consequência da guerra, haveria a queda do czarismo na Rússia e dos Hohenzollern e Habsburgos na Alemanha, isto é, haveria uma predominância da civilização ocidental sobre as formas tradicionais de dominação. Lukács está preocupado, contudo, com um outro aspecto desses acontecimentos: "Mas a questão é de saber quem irá nos salvar da civilização ocidental" (LuKÁcs ["Avant-propos [1962]", La théorie du roman] apud LöwY, 1976: 132). O posicionamento de Lukács nos remete mais uma vez ao caráter radical de sua crítica da sociedade burguesa ocidental, crítica que Löwy considera estar apoiada sobre uma "ética de esquerda utópico-idealista" (LÖWY, 1976: 131).

Arato e Breines também conferem à guerra um importante papel no desenvolvimento intelectual de Lukács. Segundo os autores (ARATO; BREINES, 1986: 99), ela é responsável pela linha divisória entre os escritos de Lukács sobre a filosofia da arte e A teoria do romance, e marca especialmente o processo no qual a atenção de Lukács fica cada vez mais distante da estética, da estetização da vida como utopia artística e como "solução" para as antinomias do presente, e aproxima-se cada vez mais de questões éticas (ARATO; BREINES, 1986: 102-103). Ele trata também de questões políticas, mas as subordina completamente a um idealismo ético: a ética deve dominar a política e as instituições políticas devem ser somente meios ou instrumentos para a realização de um fim ético (ARATO; BREINES, 1986: 122; LöWY, 1976, p. 148). Tais instituições devem ser abandonadas assim que se tornarem estáveis, porque se tornam assim fins em si mesmas e, portanto, assumem uma posição conservadora (ARATO; BREINES, 1986: 124; LÖWY, 1976, pp. 148-149). É possível perceber aqui, nos lembra Löwy, o eco da ética kantiana, segundo a qual o 
| 114 |

Considerações biográfico-intelectuais sobre...

homem não pode ser tratado nunca apenas como meio, mas sempre como um fim em si mesmo (LöWY, 1976: 150).

Essa supremacia da ética ainda marca a reação inicial de Lukács à Revolução Russa de 1917. Esse acontecimento apareceu para o filósofo como a realização de uma esperança messiânica, como o começo do fim da "época da perfeita culpabilidade". Desse modo, a revolução tinha, para Lukács, ainda uma forte "carga ético-religiosa, milenarista, dostoievskiana", e não era essencialmente política ou social (LöWY, 1990: 65). A politização propriamente dita de Lukács se dá entre os anos 1917 e 1918, período em que sofre a influência do sindicalismo revolucionário de Ervin Szabó e começa a ler anarco-sindicalistas, a extremaesquerda holandesa, Rosa Luxemburgo e Georges Sorel (LöwY, 1976: 145). No início desse movimento, contudo, Lukács ainda tem reservas quanto ao socialismo e o bolchevismo: para o filósofo, apesar de o proletariado aparecer como a classe social portadora da "redenção social da humanidade" (LukÁcs ["Le bolchevisme comme problème moral"] apud LöwY, 1990: 65), a ideologia do proletariado não é capaz de criar uma ética que abarque a todos os aspectos da vida (LöwY, 1976: 145-146). Além disso, por um lado, é verdade que ele já mantinha uma esperança no proletariado como agente social concreto da renovação da cultura e da vida, que levaria a um "[...] 'novo predomínio do geral sobre o pessoal, da comunidade sobre a liberdade isolada [...] a uma nova universalidade' que superasse o racionalismo e o individualismo fragmentado do mundo burguês" (Arato; BREINES, 1986: 92); mas, por outro lado, essa universalidade não tinha ainda um conteúdo positivo, e permanecia assim apenas como uma esperança - e inclusive uma esperança um tanto distante, tendo em vista a tendência ao individualismo e o "aburguesamento" do proletariado que Lukács observa na Alemanha (ARATO; BREINES, 1986: 92-93).

Essas e outras dificuldades que separavam Lukács do bolchevismo foram superadas ao fim do ano de 1918, quando ele adere ao Partido Comunista Húngaro. Assim, há cada vez menos espaço no pensamento de Lukács para o que Löwy chama de 
uma "visão messiânica e romântica", de forma que o sonho místico de redenção que o filósofo húngaro via na revolução russa se converte em fascinação política pela revolução bolchevique (LöWY, 1976: 145).

Surgiu assim também a possibilidade de uma nova relação com a teoria marxista, de vê-la como uma teoria dialética, diferentemente do interesse meramente "sociológico" por Marx que havia antes no pensamento de Lukács - pensamento que é caracterizado por Arato e Breines como "A combinação de uma resignada sociologia marxista da decadência cultural com uma postura ética baseada na difícil conjugação de Kant, Fichte, Kierkegaard e Dostoievski" (ARATO; Breines, 1986: 124). Nessa época, então, Lukács tem uma compreensão parcial e fragmentária do marxismo, marcada por sua visão utópica, radical e trágica. Os mesmos autores sublinham que, em diversas obras entre 1910 e 1919,

[...] se repete o argumento de que o materialismo histórico enquanto sociologia da cultura é um método capital para o estudo das condições sociológicas da possibilidade de criar obras de arte ('espírito absoluto'); mas que degenera em uma filosofia metafísica da história totalmente inaceitável no momento em que se trata de usá-la para deduzir, reduzir ou funcionalizar as grandes formas da arte ou o processo criador mesmo (ARATO; BREINES, 1986: 98).

Lukács, portanto, na sua fase pré-marxista, aceita a distinção revisionista entre ciência e revolução na obra de Marx, interessando-se primordialmente pelo lado da ciência - sua leitura de Marx não é uma leitura "revolucionária". ${ }^{16} \mathrm{Na}$ realidade, a relação de Lukács com Marx antes do período de transição

16 “[...] ainda que, vista no contexto do pensamento marxista da época, [sua leitura de Marx] resulte mais complexa do que parece" (ARATO; BREINES, 1986: 96-97). 
$|116|$

Considerações biográfico-intelectuais sobre...

compreendido entre 1918-1921 não é algo simples. Curiosamente, notam Arato e Breines, nesse período anterior, Lukács apresenta análises mais passivas da realidade justamente quando se aproxima de Marx (numa leitura "sociológica"), e mostra traços mais revolucionários quando se afasta dele (ARATO; BREINES, 1986: 95-96). Além disso, Karádi afirma que: “Talvez nós pudéssemos ir ao ponto de sugerir que, na época, Weber estava mais próximo do marxismo que Lukács" (KARÁDI, 1987: 508).

Não cabe aqui, entretanto, investigar todos os fatores que levaram Lukács a uma nova compreensão do marxismo. O que importa aqui é destacar que, agora, o filósofo húngaro lê Marx não mais como homem de ciência, economista ou sociólogo, mas como "pensador universal", como "o grande dialético" (LuKÁcs ["Mein Weg zu Marx"] apud LöwY, 1976: 144). Já durante a guerra, Lukács se ocupa pela segunda vez de Marx ${ }_{1}^{17}$ mas dessa vez sob uma lente hegeliana (conferindo assim um papel central à categoria da totalidade) e não mais simmeliana e weberiana (isto é, com um interesse fundamentalmente sociológico) como antes.

O próprio Lukács, pondera, em seu prefácio de 1967 a História e Consciência de Classe, sobre a sua trajetória intelectual; referindo-se às diferentes tendências que estavam presentes na sua juventude, ele afirma:

A ética, por exemplo, impele à prática, ao ato e, assim, à política. Esta, por sua vez, impele à economia, o que leva a um aprofundamento teórico e, por fim, à filosofia do marxismo. Trata-se, naturalmente de tendências que se desdobram apenas de maneira lenta e irregular (LuKÁcs, 2003: 5, “Prefácio [1967]”).

\footnotetext{
17 Ele havia lido Marx pela primeira vez ao terminar os estudos secundários e quando era estudante universitário (LuKÁcs, 1988: 85).
} 
Como se pode imaginar, todo esse movimento político e intelectual de Lukács o afastou cada vez mais de Weber. Éva Karádi nos traz um rico material sobre esse afastamento: a autora aponta que Lukács escreveu uma carta a Marianne Weber em que diz que seu contato com Max Weber poderia se dar somente nos termos de "antigos amigos que, apesar de gostarem um do outro mutuamente, estavam condenados a destruir um ao outro" (LuKÁCs [carta] apud KARÁDI, 1987: 509). Quanto a Weber, Karádi afirma que, em cartas ao pai de Lukács, ele se mostrava bastante descontente com o caminho que filósofo estava tomando, ao envolver-se com política (e da forma como ele o estava fazendo) - mas respeitava a decisão de Lukács. Em uma outra carta a Marianne Weber, datada de 1920, entretanto, Lukács afirma que "Tudo o que nos divide [...] poderia ser demolido, destruído por algumas palavras entre seres humanos" (idem, ibidem). Weber morreu pouco tempo depois e essas palavras, diz Karádi, nunca puderam ser ditas, e o diálogo entre os dois pensadores se transformou num monólogo.

De fato, nas décadas após a morte de Weber (em 1920), Lukács reflete em diversos escritos sobre o sociólogo de Heidelberg e sua obra. O comentador Zoltan Tarr chega a afirmar que, assim como na famosa metáfora de Albert Salomon, segundo a qual Weber escreveu toda a sua obra debatendo com o fantasma de Marx, pode-se considerar que a obra de Lukács é marcada pela "discussão" com o fantasma das ideias de Max Weber (TARR, 1989: 131). Com o passar do tempo, a visão lukácsiana da obra de Weber vai ficando cada vez mais crítica, sendo que em 1953, em A destruição da razão, ele o coloca entre os intelectuais irracionalistas que, mesmo que involuntariamente, foram precursores do fascismo.

Por outro lado, já em 1966, em entrevista a Abendroth, Kofler e Holz, Lukács afirma que foi bom começar a aprender "os primeiros elementos da ciência social com Simmel e Max Weber, e não com Kautsky" (Lukács [entrevista] apud Löwy, 1990: 80). No mesmo sentido, no novo prefácio a História e Consciência de Classe e outros escritos de juventude (escrito em 1967), ele 
| 118 |

Considerações biográfico-intelectuais sobre...

reconhece a medida em que as posições presentes tanto nessa obra de transição quanto em obras anteriores à sua adesão ao marxismo foram importantes para a sua formação - inclusive para a sua formação como marxista.

\section{Bibliografia}

ARATO, Andrew; Breines, Paul. El joven Lukács y los orígenes de lo marxismo occidental. México D. F.: Fondo de Cultura Económica.1986.

CONGDON, Lee The Young Lukács. The University of North Carolina Press.

FEENBERG, Andrew [1986]. Lukács, Marx, and the sources of critical theory. New York/Oxford: Oxford University Press.1983

HABERMAS, Jürgen. "From Lukács to Adorno: Rationalization as Reification" in Theory of communicative action, vol. 1. Boston: Beacon Press.1984.

Honigsheim, Paul. "Memories of Max Weber", in: On Max Weber. Tradução de Joan Rytina. New York: Free.1968.

KARÁDI, Éva [1987]. “Ernst Bloch and Georg Lukács in Max Weber's Heidelberg", in: Mommsen, W., Osterhammel, J. (eds.). Max Weber and his contemporaries. London: Unwin Hyman, pp. 499-514.

LÖWY, Michel . Pour une sociologie des intellectuels révolutionnaires. Paris: PUF.1976.

. Romantismo e Messianismo. São Paulo: Perspectiva/ Edusp.1990.

[s/d]. "Figuras do marxismo weberiano". Disponível em http://antivalor2.vilabol.uol.com.br/textos/outros/ lowy_01.html, acessado em 22/11/2009.

LUKÁCS, Georg . "Meu caminho para Marx", in: Chasin, J. (org.), Marx Hoje, v.1. São Paulo: Ensaio, pp. 119-135.1988 . História e Consciência de Classe. Tradução de R. Nascimento. São Paulo: Martins Fontes. 2003. 
MÉSZÁROS, István. “Lukács, György [Georg]" in: BотTOMORE, T. (ed.). Dicionário do pensamento marxista. Rio de Janeiro: Jorge Zahar.1996.

MITZMAN, Arthur. La jaula de hierro - una interpretación histórica de Max Weber. Tradução de A. S. Pascual e M. D. C. Lobera. Madrid: Alianza Editorial. 1976.

NOBRE, Marcos. Lukács e os limites da reificação. São Paulo: Ed. 34.2001.

TARR, Zoltan. "A note on Weber and Lukács" in: International Journal of Politics, Culture and Society, vol. 3, n. 1, pp. 131-139.1989.

WEBER, Max. "Ciência como vocação", in: Ciência e Política: duas vocações. Tradução de L. Hegenberg e O. S. Mota. São Paulo: Cultrix.1970. 